\title{
Post-co? Przydatność kategorii „postsocjalizmu” w badaniach antropologicznych w byłej Jugosławii ${ }^{1}$
}

\section{Abstract}

\section{Post-What? The Category of „Postsocjalism” and Its Usefulness in Anthropological Research in the Former Yugoslavia}

The aim of this paper is a look into a notion of "ostsocialism" in the context of anthropological research in former Yugoslavia. After a short overview of the definitions of postsocialism, I argue, that this concept is defined too broadly in order to capture complexity of social and cultural life in various post-socialist or post-communist states. In the case of former Yugoslavia I suggest using the term "post-Yugoslav" in order to show a specifics of life in socialist Yugoslavia and in the republics emerged after its collapse. My arguments base on the data collected during ethnographic fieldwork in the Republic of Macedonia.

Keywords: postsocialism, former Yugoslavia, Macedonia, East and West, Europe

Postsocjalizm jest bardzo pojemną kategorią, używaną w naukach społecznych w celu zrozumienia i opisu fenomenów, praktyk, wartości czy instytucji kulturowych i społecznych w społecznościach, które przeszły lub przechodzą transformację od państwowych socjalizmów do gospodarki wolnorynkowej i systemu wielopartyjnego (Verdery 1996).

1 Artykuł powstał na podstawie badań przeprowadzonych w ramach projektu „Macedońskie Porecze w 80 lat po badaniach Józefa Obrębskiego. Antropologiczne studium ciągłości i zmiany” finansowanego ze środków Narodowego Centrum Nauki, nr grantu: 2011/01/D/HS3/03583. 
Część autorów traktuje łącznie wszystkie kraje od ZSRR po Jugosławię (Katherine Verdery twierdzi, że różnice są mniejsze niż podobieństwa, choć chyba o samej Jugosławii pisze się stosunkowo najmniej, zob. Gilbert et al. 2008), postuluje się też połączenie studiów postkolonialnych z postsocjalistycznymi pod wspólnym mianem „studiów postzimnowojennych” (Chari, Vedery 2009).

Jak słusznie zauważa Hana Cervinkova, studia postkolonialne zapoczątkowali badacze $\mathrm{z}$ byłych kolonii, a postsocjalizm jest kategorią zaproponowaną przez badaczy z Zachodu (2012: 159), początkowo mającą znaczenie temporalne - odnoszącą się do czasu po upadku komunizmów i realnych socjalizmów (2012: 156). Warto w tym kontekście przywołać refleksję Michała Buchowskiego dotyczącą hierarchii wiedzy. Otóż zauważa on, że w publikacjach autorów z Europy Zachodniej i USA dotyczących Europy Środkowej i Wschodniej rzadko pojawiają się odwołania do prac lokalnych badaczy. A już na pewno nie do etnografów czy antropologów (Buchowski 2004).

Powstaje więc pytanie, czy w ogóle kategoria postsocjalizmu ma sens? Czy po pierwsze nie jest zbyt pojemna i przez to nieostra, a po drugie zewnętrzna, zachodnia, entocentryczna - takich „obelg” można by wymienić więcej. Po trzecie wreszcie, czy ta kategoria pozwala nam na wyjście poza zajmowanie się sytuacją gospodarczą, prawną i polityczną, a skupienie się na innych zagadnieniach, poruszanych zwłaszcza przez antropologów: uwarunkowaniach i przemianach społecznych oraz kulturowych. Innymi słowy, czy kategoria postsocjalizmu pozwala na zrozumienie praktyk, wyobrażeń, dyskursów i narracji ludzi po upadku komunizmów i socjalizmów.

Mimo że wąską definicję socjalizmu (jednopartyjny system i brak własności prywatnej) można zastosować do każdego kraju tak zwanego bloku wschodniego, to jednak poziom życia (mam tu na myśli status ekonomiczny, ale również skalę opresji i nierównomierny dostęp do dóbr) obywateli w wielu krajach był nieporównywalny.

Celem tego artykułu jest pokazanie, że kategoria postsocjalizmu może być przydatna w badaniach antropologicznych w byłej Jugosławii. Zgadzam się bowiem ze stwierdzeniem Chrisa Hanna, że „termin postsocjalizm będzie aktualny dopóty, dopóki idee, ideologie i praktyki socjalizmu będą uważane za istotny punkt odniesienia dla zrozumienia współczesnej kondycji ludzkiej" (Hann 2004: 3). Zarówno z moich własnych badań terenowych w Macedonii, jak i analizy literatury przedmiotu wynika, że Jugosławia nadal stanowi ważny punkt odniesienia dla mieszkańców byłych republik. Jednak, po pierwsze, należy najpierw pokazać zniuansowanie socjalizmu i postsocjalizmu w (byłej) Jugosławii, a po drugie, termin „postsocjalizm” jako zbyt pojemny lepiej zastąpić terminem emic, czyli postjugosłowiański. 


\section{(Post)socjalizm w Jugosławii}

Jugosławia była krajem socjalistycznym, a zatem można tu mówić o pewnej odmianie postsocjalizmu. Zresztą w publikacjach dotyczących byłej Jugosławii sam termin „postsocjalizm” się pojawia. Pozostaje tylko pytanie, na czym on polega.

W przeciwieństwie do innych krajów Europy Zachodniej Jugosławia nigdy nie została „wyzwolona” przez Związek Radziecki, ale przez partyzantkę Josipa Broza-Tity, której członkowie zostali później przedstawicielami elit rządzących (Luthar, Pušnik 2010: 5). Jednocześnie, podobnie jak w innych krajach socjalistycznych i komunistycznych, wprowadzono centralne planowanie, kult pracy fizycznej czy plany pięcioletnie, a budowa społeczeństwa socjalistycznego $\mathrm{w}$ znacznej mierze opierała się na masowej pracy nieodpłatnej (tzw. czynie społecznym) (Luthar, Pušnik 2010: 5). Niemniej radziecki model socjalizmu został tu zmodyfikowany. Dla obywateli szczególnie znacząca była większa otwartość na Zachód. Do roku 1967 zostały zniesione wszystkie wizy dla obywateli Jugosławii oraz otwarto granice dla obcokrajowców odwiedzających Jugosławię. Znacząca była również wymiana kulturalna i ekonomiczna z Zachodem, na przykład możliwość ubiegania się o kredyty na Zachodzie, ułatwione podróżowanie i praca w Europie Zachodniej (Luthar, Pušnik 2010: 7).

Jeśli rozumiemy postsocjalizm jako proces demokratyzacji, prywatyzacji, urynkowienia, ale także europeizacji i lustracji - to być może była Jugosławia tego procesu (jeszcze) nie przeszła albo przechodzi go inaczej niż inne kraje dawnego bloku wschodniego. Jednym z rozwiązań terminologicznych jest rozróżnienie Stevena Sampsona na postsocjalizm (transformację) i postpostsocjalizm (Sampson 2002). Jeszcze innym terminem, za którym się opowiadam, jest nawiązujący do konkretnego przypadku, tu Jugosławii, czyli post-Jugosławii, „postjugosłowiański”. Poniżej postaram się zanalizować w tym kontekście kilka kwestii.

Andrew Gilbert (2006) zauważa, że w Bośni nie możemy mówić o postsocjalizmie, ponieważ zamiast transformacji czy bezpośrednio po socjalizmie wybuchła wojna. W 2003 roku w 10 tysiącach egzemplarzy wydano cztery tomy Čuvari Jugoslavije (Strażnicy Jugosławii), w których opracowano ponad 1300 teczek osób współpracujących z systemem bezpieczeństwa w Jugosławii (UDBA - Uprava državne bezbjednosti), ponad 5000 pozostało nieopublikowanych. Dyskusja trwała kilka tygodni, a następnie ucichła. Zupełnie inaczej niż w innych krajach, jak Polska, byłe NRD czy Czechosłowacja, gdzie lustracja była szeroko i burzliwie dyskutowana. Dla Bośniaków istotne okazało się rozliczenie nie tyle współpracowników poprzedniego systemu, ile zbrodniarzy wojennych. Jak pisze Gilbert: „Pewien znany intelektualista $\mathrm{z}$ Sarajewa powiedział mi, że chętniej żyłby razem z takimi «informatorami» niż z ludźmi pokroju Radowana Karadzicia, który nie znalazł się na liście kolaborantów" (Gilbert 2006: 14). Autor postuluje więc, żeby mówić o Bośni powojennej, a nie postsocjalistycznej. 
Kolejną kwestią jest dyskusja nad zjawiskiem nostalgii, a także nad konstrukcjami „Wschodu” i „Zachodu” czy „Europy” i „Bałkanów”. Jednym z wątków poruszanych przez autorów - od literaturoznawców, przez historyków, do antropologów i socjologów - jest pojęcie nostalgii, tu zwanej ,jugonostalgią”. Notabene, co ciekawe, w tekstach dotyczących nostalgii pojawia się odwołanie do komunizmu, a nie socjalizmu, na przykład Post-communist Nostalgia pod redakcją Marii Todorowej i Zsuzsy Gille czy Nostalgia. Eseje o tęsknocie za komunizmem pod redakcją Moniki Sznajderman i Filipa Modrzejewskiego. Zapewne siła tego ostatniego słowa jest większa. Peter Skalník słusznie dowodzi, że wprawdzie w zachodniej nauce poprzedni system nazywany jest „socjalizmem” lub „realnym socjalizmem”, ale w krajach Europy Wschodniej mówi się o nim „komunizm” i „postkomunizm” (Skalník 2002: 194), po polsku natomiast zwykle: „za komuny”. Ilká Thiessen idzie dalej, pisząc, że w ogóle Europa Wschodnia jest konstruowana przez Zachodnią, czego wynikiem jest choćby pojęcie postsocjalizmu (2007: 11-12). Tęsknota - podobnie jak w innych krajach - dotyczy przede wszystkim dnia codziennego, pewnych artefaktów, produktów, filmów, muzyki i wreszcie odnosi się do młodości, która zwykle jest wspominana pozytywnie.

W moich badaniach migrantów-muzułmanów przemieszczających się z Macedonii do Włoch (Bielenin-Lenczowska 2015) kategoria „Europy” i „Zachodu” pozwalała moim rozmówcom na wyjaśnienie ich kondycji i sytuacji życia za granicą. Pojęcie „Zachodu” okazuje się równoznaczne z nowoczesnością (Jas sum moderen - jestem nowoczesny - często mówią rozmówcy). Nowocześni są ci, którzy wyjechali za granicę, w opozycji do tych, którzy nie emigrowali - oni są „zacofani” (zaostanati). Migranci mieszkają bowiem na Zachodzie ${ }^{2}$, w Europie, a nie w Macedonii, która w tym rozumieniu Europą nie jest (Petrovic 2011), tylko - usytuowanymi w opozycji do Europy - Bałkanami (Todorova 2008).

Jugosławia, jak wspomniałam, była o wiele bardziej otwarta na Zachód niż inne kraje bloku wschodniego, żadnego muru - ani rzeczywistego, ani symbolicznego - nie było. Dostęp do dóbr, usług i wiedzy był dla mieszkańców Jugosławii nieporównywalnie łatwiejszy niż w ZSRR czy jego satelitach. Nie oznacza to jednak, że obywatele Jugosławii nie doświadczali opresji ze strony państwa czy że ich sytuacja ekonomiczna była taka sama jak w krajach Europy Zachodniej. Nie można zapomnieć choćby o Nagiej Wyspie (Goli Otok) - miejscu obozu koncentracyjnego dla przeciwników politycznych Josipa Broza-Tity - czy o masowej emigracji zarobkowej po podpisaniu umów o pracownikach gościnnych (Gastarbeiters) do Niemiec i w mniejszym stopniu do Austrii, Szwajcarii, Belgii i Holandii. W Jugosławii z umów tych korzystali przede wszystkim mieszkańcy najuboższych republik, czyli Kosowa, Macedonii oraz Bośni i Hercegowiny (Markov 2013: 250; Dimova 2007: 2-3). Program trwał od 1968 do 1973 roku, do czasu kryzysu naftowego w Europie. Jak zauważa Mila Maeva, „największa

${ }^{2}$ Zachód jest tu pewną konstrukcją kulturową, a nie (tylko) kierunkiem geograficznym. Zachodnią Europą są tu bowiem np. Włochy czy Austria. 
fala migracji z Jugosławii została zanotowana w 1973 roku (...), kiedy emigranci osiągnęli liczbę 1,1 miliona, z czego 860000 były to osoby aktywne ekonomicznie, a 250000 to członkowie rodzin" (Maeva 2010: 188). Ponadto, jak słusznie zauważa Dean Vuletic, Jugosławia, mimo że otwarta na Zachód i z nim powiązana, była jednak mniej uprzywilejowana politycznie i ekonomicznie. Jugosławia była niejako pod stałą obserwacją Zachodu jako ten jej „Obcy” lub „Wschodni” (orientalizacja czy „bałkanizacja” Jugosławii jest tu szczególnie widoczna). Vuletic, prowadząc badania nad udziałem Jugosławii w konkursie Eurowizji (do początku lat 90. jako jedynego kraju socjalistycznego), pokazuje, że Jugosławia była jednak i uboższa, i - kulturowo, symbolicznie - odmienna od Zachodu. Konkurs Eurowizji pokazał - pisze Vuletic - że Jugosławia jest z jednej strony liberalnym i otwartym krajem, ale $z$ drugiej - podobnie jak w innych krajach Europy Wschodniej - wolność artystyczna i polityczna jest tam ograniczona, a środki finansowe na promowanie piosenkarzy oraz kampanie znacznie skromniejsze niż w Europie Zachodniej. Możliwość udziału Jugosławii w Eurowizji maskowała te ograniczenia (Vuletic 2010: 122). W podobnym duchu pisze Breda Luthar, która analizowała praktykę wyjeżdżania za zakupy z Jugosławii do Włoch (Triest) pomiędzy 1955 rokiem a końcem lat 60. Autorka zwraca uwagę, że w Jugosławii - podobnie jak w innych krajach socjalistycznych i komunistycznych - potrzeby konsumpcyjne były limitowane i kontrolowane przez władzę (autorka rozwija tu koncepcję „dyktatury nad potrzebami” - dictatorhip over needs - Ferenca Fehera $i$ in. 1983), a samo pojęcie „potrzeby" silnie upolitycznione i zdefiniowane w kategoriach etycznych, to jest ograniczenie konsumpcji miało być politycznym i moralnym obowiązkiem obywateli (Luthar 2010: 346). I mimo że granice Jugosławii otwarły się na Zachód i można było swobodnie podróżować, zarówno instytucje państwowe, jak i sami obywatele musieli wypracować pewne strategie pozwalające na przekraczanie granicy, kupowanie towarów niedostępnych czy uważanych za lepsze i przewożenie ich z powrotem do Jugosławii. Ponieważ wiele z tych praktyk było nielegalnych (np. przewożenie zbyt dużej ilości towaru lub przemycanie "twardej waluty"), wytworzyła się specyficzna wiedza przekazywana drogą ustną - w jaki sposób coś przewieźć, który z celników jest przyjazny czy jak się zachować podczas kontroli (Luthar 2010: 359).

Wyjazdy na zakupy do Triestu nie były jedynie sposobem zaspokojenia podstawowych potrzeb konsumpcyjnych obywateli Jugosławii. Była to również próba manifestacji przynależności do konsumpcyjnej kultury zachodniej - poprzez kupowanie i konsumowanie dóbr czy poprzez zdobytą za granicą wiedzę.

Pisząc o specyfice Jugosławii, należy pamiętać o pokazanych wyżej ograniczeniach, ponieważ we współczesnych narracjach mieszkańców byłej federacji Jugosławię niemalże utożsamia się z krajami Europy Zachodniej. Warto zatem pokazać różnice także pomiędzy Jugosławią a innymi państwami bloku wschodniego oraz porównać sytuację sprzed rozpadu federacji do tej po nim. Ponieważ po socjalizmie w Jugosławii trwała wojna i następował podział na mniejsze kra- 
je, borykające się z problemami politycznymi, napięciami etnicznymi i kryzysem ekonomicznym, postsocjalizm też jest inny niż tam, gdzie po upadku komunizmów i socjalizmów zaczęła się transformacja.

W krajach postjugosłowiańskich w narracjach mieszkańców byłej federacji wyraźna jest tęsknota do wielkości i znaczenia tamtego państwa, a także do wspomnianej już wyżej - otwartości na Zachód i niemal utożsamiania Jugosławii z Europą Zachodnią. Jest to szczególnie widoczne w małych i niestabilnych ekonomicznie oraz politycznie krajach, jak Macedonia. Do 2009 roku, czyli do czasu zniesienia reżimu wizowego, z Macedonii bez wizy można było pojechać do Bułgarii, Serbii i Grecji. Oto słowa jednego z Macedończyków, regularnie wyjeżdżającego do Słowenii w celach zarobkowych: „W pewnym momencie nie mogłem pojechać. Mój macedoński paszport okazał się nieważny, trzeba było do Skopja do ambasady jechać, jakieś papiery wypełniać, pisać po co i do kogo. Jak to tak? W to samo miejsce, gdzie co roku, do tych samych ludzi. Mam tam rodzinę i nie mogę ich zwyczajnie odwiedzić” (mężczyzna, ok. 50 lat, Prilep 2005).

Wreszcie pytanie dotyczy tego, kiedy zaczyna się postsocjalizm i czy jest on czasem transformacji czy już po niej. Wspomniany wyżej Sampson mówi o postsocjalizmie jako czasie transformacji, po niej zaś następuje postpostsocjalizm (Sampson 2002). Wielu Macedończyków twierdzi, że ich kraj nadal przechodzi transformację. Wszystko jest tymczasowe, nawet nazwa - Była Jugosłowiańska Republika Macedonii. Zsuzsa Gille zauważa, że mieszkańcy krajów socjalistycznych tęsknili za normalnością. Oznaczała ona dla nich życie bez ciągłego upolitycznienia („marzę o życiu w małym, nudnym europejskim kraju” - powiedział swego czasu Vaclav Havel; Gille 2010: 20). Tymczasem, jak wynika z badań Ilki Thiessen (2007; zob. też Gilbert et al. 2008), która zajmowała się młodymi inżynierkami w Skopju w latach 90., normalnością było życie w Jugosławii - stała praca, dostęp do bezpłatnej edukacji, możliwość podróżowania czy przewidywalność życia codziennego. To, co stało się po rozpadzie Jugosławii, było chaosem.

Podczas gdy projekt modernizacyjny dla krajów socjalistycznych zakładał podążanie drogą rozwoju Europy Zachodniej (jak zauważają Katherine Verdery i Sharad Chari, krytykowano politykę, gospodarkę czy kulturę socjalistyczną, a postsocjalizm miał być niejako „, antysocjalizmem”), transformacja w byłej Jugosławii (znów odwołuję się do Macedonii) była postrzegana jako cofnięcie się: nowoczesna, europejska i zachodnia - była Jugosławia, zacofana, biedna i bałkańska - Macedonia lat 90. (Thiessen 2007). W Jugosławii - mimo że była to rola narzucona - kobiety mogły realizować się zawodowo i wychowywać dzieci - po jej rozpadzie ani nie było pracy dla kobiet, ani państwo nie zapewniło opieki dzieciom. Znaczącym przykładem jest choćby wieś Samokow w środkowej Macedonii, gdzie prowadziłam badania ze studentami w 2012 i 2013 roku (Bielenin-Lenczowska 2015b). Tam jeszcze do 2005 roku istniała fabryka broni „Suvenir”. W czasach jej świetności, czyli w latach 70., 80., większość mieszkanek i mieszkańców Samokowa pracowała $\mathrm{w}$ fabryce. Od pracodawcy otrzymali ziemię pod budowę domu, 
ich dzieci chodziły do przyzakładowego żłobka i przedszkola, mężczyźni popołudniami grali w piłkę w przyzakładowym klubie, udzielano dofinansowania na wakacje nad Adriatykiem i tak dalej. Obecnie okolica się wyludnia, ponieważ nie ma pracy, a ludzie nie mają zaufania do władz kraju. Bardzo silnie w narracjach mieszkańców obecna jest Jugosławia, za czasów której nie tylko ludziom żyło się lepiej pod względem finansowym, ale również byli spokojniejsi o przyszłość swoją i swoich dzieci (Thiessen 2007; Chajęcka 2015). Podział na „Bałkany” i „Europę” jest też obecny wewnątrz kraju - europejscy są młodzi wykształceni Macedończycy, bałkańscy - wiejscy, niewykształceni Albańczycy z wysokim przyrostem naturalnym, w dodatku muzułmanie. Oczywiście jest to pewien stereotyp, ale chętnie powielany. Jednocześnie, podobnie jak w innych krajach postsocjalistycznych, choćby w Polsce (zob. np. Buchowski 2012; Rakowski 2009), w Macedonii widoczny jest dyskurs wpisywania "przegranych transformacji” (bezrobotnych, wykluczonych politycznie i ekonomicznie) w kategorie tego, co zachodnie-niezachodnie i europejskie-bałkańskie. Jak zauważa jednak Patrycja Chajęcka, mieszkańcy Samokowa i okolic, mimo trudnych warunków finansowych i życia na prowincji, mają wiele zróżnicowanych strategii przetrwania - uczą się nowych sposobów zarobkowania, żyją z rolnictwa i zbieractwa (Chajęcka 2015; zob. też Rakowski 2009). Wśród tych strategii są też znane $z$ innych krajów postsocjalistycznych „znajomości” (mac. vrzki). „W Skopije - zauważa Thiessen w odniesieniu do lat 90. - nikt z ludzi, których znam, nie dostał pracy bez znajomości” (Thiessen 2007: 90). Podobnie pisze Chajęcka, która podaje przykłady narracji na temat strategii ekonomicznych, w których przewija się (znany również choćby z badań w Polsce) wątek narzekania. Narzeka się na biedę, ale przede wszystkim na państwo (niekoniecznie na konkretnych polityków czy instytucje), w którym zdobycie pracy, pożądanego zawodu czy uzyskanie zasiłku wiąże się z posiadaniem odpowiednich kontaktów (Chajęcka 2015: 55; zob. też Buchowski 2012: 77).

Cytowana już Zsuzsa Gille zwraca uwagę, że nie możemy patrzeć na politykę socjalistyczną przez pryzmat tylko dystrybucji (i wychodząc z założenia, że kapitalizm wiąże się z polityką uznania), ale że transformację należy rozumieć jako przejście do innego rodzaju polityki uznania, bazującej obecnie na płynnych, zmiennych tożsamościach. Oczywiście przekłada się to też na dystrybucję i uprzywilejowanie lub dyskryminację różnych grup ludzi. Podczas gdy w czasach socjalistycznych koncentrowano się na przynależności klasowej, w postsocjalizmie mamy do czynienia $\mathrm{z}$ innego rodzaju wykluczeniami i dyskryminacją, bazującymi na innych kryteriach (Gille np. mówi o tyranii uczestnictwa w UE). W Jugosławii czynnik etniczny i - co pokazała wojna - narodowy były i nadal są niezwykle istotne. Mimo że Tito starał się stosować równy podział dóbr, i na przykład wprowadził dla wyznawców islamu w 1961 roku kategorię „narodowość, a w 1971 "naród” (wtedy muzułmanów, od 1995 roku to Boszniacy), to jednak pewne elementy polityki wykluczającej były widoczne. Przykładem jest choćby zakaz zakrywania twarzy (feredże) przez kobiety muzułmańskie wprowadzony 
w 1950 roku. Miał on na celu wyrównanie szans muzułmanek na przykład na rynku pracy i w edukacji, a okazał się inną formą opresji - wiele szanujących się muzułmanek wcale nie chciało wychodzić z domów „nieubrane” (zob. BieleninLenczowska 2015).

W przypadku analizy sytuacji w Jugosławii i zmian po jej rozpadzie proponowałabym chyba najprostsze rozwiązanie - termin post-Jugosławia, postjugosłowiański, który byłby pewną odmianą, uszczegółowieniem postsocjalizmu. Ma on, podobnie jak postsocjalizm, znaczenie temporalne, oznacza pewną epokę oraz wskazuje na ważny związek z byłym państwem. W przeciwieństwie do niektórych definicji postsocjalizmu przedrostek "post” nie oznacza jednak „anty”. Do pewnych rozwiązań w polityce nadal się odnosi i do nich tęskni (łącznie z samym przywódcą, przykładem niech będzie książka Mitji Velikonji Titostalgija). Ponadto jest to termin o wiele bardziej emic niż postsocjalizm, ponieważ znacznie bardziej odnosi się do tego, jak sami mieszkańcy byłej Jugosławii mówią o poprzedniej epoce (np. mac. za vreme na Jugoslavija). Pozwala on także wyjść poza skalę makro i skupić się na działaniach, strategiach i sprawczości poszczególnych aktorów społecznych w życiu codziennym. Wreszcie daje możliwość wykroczenia poza jedną kategorię „socjalistycznych” czy „komunistycznych” wyobrażeń oraz praktyk i porównania doświadczeń z Jugosławii z tymi z innych obszarów dawnego bloku wschodniego.

\section{Bibliografia}

Bielenin-Lenczowska K.

2015a Spaghetti z ajwarem. Translokalna codzienność muzułmanów w Macedonii i we Włoszech, Warszawa.

Bielenin-Lenczowska K. (ed.),

2015b Anthropology of Continuity and Change. Macedonian Poreche after 80 Years of Jozef Obrebski Research, Warszawa.

Buchowski M.

2004 Hierarchies of Knowledge in Central-Eastern European Anthropology, „Anthropology of East Europe Review", nr 22(4), s. 5-14.

2012 Anthropology in Postsocialist Europe, w: U. Kockel, M.N. Craith, J. Frykman (eds.), A Companion to the Anthropology of Europe, Chichester, s. 68-87.

Cervinkova $\mathrm{H}$.

2012 Postcolonialism, Postsocialism and the Anthropology of East-central Europe, „Journal of Postcolonial Writing", nr 48(2), s. 155-163.

Chajęcka P.

2015 Narrative and Economic Strategies of Coping with Crisis in the Macedonian Region of Poreche, w: K. Bielenin-Lenczowska (ed.), Anthropology of Continuity and Change. Macedonian Poreche after 80 Years of Jozef Obrebski Research, Warszawa, s. 49-69.

Chari S., Verdery K.

2009 Thinking between the Posts: Postcolonialism, Postsocialism, and Ethnography after the Cold War, „Comparative Studies in Society and History”, nr 51(1), s. 6-34. 


\section{Dimova R.}

2007 From Past Necessity to Contemporary Friction: Migration, Class and Ethnicity in Macedonia. Working Paper 94, Halle, http://eth.mpg.de/cms/en/publications/working_papers/pdf/mpi-eth-working-paper-0094.pdf (dostęp: 05.04.2014).

Feher F., Heller A., Markus G.

1983 Dictatorship over Needs, Oxford.

Gilbert A.

2006 The Past in Parenthesis. (Non)post-socialism in Post-war Bosnia-Herzegovina, „Anthropology Today”, nr 22(4), s. 14-18.

Gilbert A. et al.

2008 Reconsidering Postsocialism from the Margins of Europe. Hope, Time and Normalcy in Post-Yugoslav Societies, „Anthropology News”, s. 10-11.

Gille Z.

2010 Is There a Global Postsocialist Condition?, „Global Society”, nr 24(1), s. 9-30.

Hann C. (ed.)

2004 Postsocialism: Ideologies, and Practices in Eurasia, London-New York.

Luthar B.

2010 Shame, Desire and Longing for the West: A Case Study of Consumption, w: B. Luthar, M. Pušnik (eds.), Remembering Utopia: The Culture of Everyday Life in Socialist Yugoslavia, Washington, s. 341-377.

Luthar B., Pušnik M.

2010 The Lure of Utopia. Socialist Everyday Space, w: B. Luthar, M. Pušnik (eds.), Remembering Utopia: The Culture of Everyday Life in Socialist Yugoslavia, Washington, s. $1-33$.

Maeva M.

2010 The Processes of Labour Mobility and Emigration of Macedonian Muslims (Torbeshes) to Central and Western European Countries, w: P. Hristov (ed.), Balkan Migration Culture: Historical and Contemporary Cases from Bulgaria and Macedonia, Sofia, s. $182-209$.

Markov I.

2013 Migration, Remittances and Socio-cultural Dynamics: The Case of Albanians from the Republic of Macedonia, „Southeast European and Black Sea Studies”, t. 13, nr 2, s. $245-264$.

Petrovic T.

2011 Thinking Europe without Thinking. Neo-colonial Discourse on and in the Western Balkans, „Eurozine”, http://www.eurozine.com/articles/2011-09-22-petrovic-en.html (dostęp: 28.10.2014).

Rakowski T.

2009 Łowcy, zbieracze, praktycy niemocy. Etnografia człowieka zdegradowanego, Gdańsk. Sampson S.

2002 Beyond Transition: Rethinking Elite Configurations in the Balkans, w: C. Hann (ed.), Postsocialism: Ideals, Ideologies and Practices in Eurasia, London-New York, s. 297-316.

Skalník P.

2002 West Meets East or, Rather, It Finds New Exotic Lands, w: P. Skalník (ed.), A Post-Communist Millennium. The Struggles for Sociocultural Anthropology in Central and Eastern Europe, Prague, s. 185-195. 
Thiessen I.

2007 Waiting for Macedonia: Identity in a Changing World, Toronto.

Todorova M.

2008 Bałkany wyobrażone, przeł. P. Szymor, M. Budzińska, Wołowiec.

Verdery K.

1996 What Was Socialism and What Come Next, Princeton.

Vuletic D.

2010 European Sounds, Yugoslav Visions. Performing Yugoslavia at the Eurovision Song Contest, w: B. Luthar, M. Pušnik (eds.), Remembering Utopia: The Culture of Everyday Life in Socialist Yugoslavia, Washington, s. 121-144. 